BMJ Open

Sport \&

Exercise

Medicine

\section{Musculoskeletal pain and its association with maturity and sports performance in 14-year-old sport school students}

To cite: Malmborg JS, Olsson MC, Bergman S, et al. Musculoskeletal pain and its association with maturity and sports performance in 14-yearold sport school students. BMJ Open Sport \& Exercise Medicine 2018;4:e000395. doi:10.1136/ bmjsem-2018-000395

Accepted 18 June 2018

\section{Check for updates}

(c) Author(s) (or their employer(s)) 2018. Re-use permitted under CC BY-NC. No commercial re-use. See rights and permissions. Published by BMJ.

${ }^{1}$ The Rydberg Laboratory for Applied Sciences, Halmstad University, Halmstad, Sweden ${ }^{2}$ Spenshult Research and Development Center, Halmstad, Sweden

${ }^{3}$ Malmö Sports Academy, Malmö, Sweden

${ }^{4}$ Primary Health Care Unit, Department of Public Health and Community Medicine, Institute of Medicine, The Sahlgrenska Academy, University of Gothenburg, Gothenburg, Sweden

${ }^{5}$ Department of Clinical Sciences, Lund, Section of Rheumatology, Lund University, Lund, Sweden

Correspondence to MSc Julia S Malmborg; julia. soderstrom_malmborg@hh.se

\section{ABSTRACT}

Objectives In youth sports, musculoskeletal pain is often studied from the standpoint of sports injuries, but little is known about pain conditions in which athletes still participate. The aim was to study the frequency of pain and associations with maturity offset, health status and sports performance in 14-year-old sport school students. Methods Cross-sectional design. One hundred and seventy-eight students (108 boys and 70 girls) completed anthropometric measures for maturity offset (height, weight and sitting height), questionnaires (pain mannequin and EQ-5D for health status) and sports performance tests (sprint, agility, counter-movement jump and grip strength). Differences between groups were analysed with Student's $\mathrm{t}$-test and analysis of covariance.

Results Thirty-one students (18.6\%) reported infrequent pain, $85(50.9 \%)$ frequent pain and $51(30.5 \%)$ constant pain. Students in the constant pain group had worse health status than those in the infrequent pain group. Boys with constant pain $(n=27)$ had a lower mean maturity offset $(-0.38$ vs 0.07 years; $p=0.03)$ than boys with infrequent pain $(n=22)$, and pain was associated with worse sports performance. There was no difference in maturity or sports performance between girls with constant pain $(n=24)$ and girls with infrequent pain $(n=9)$.

Conclusion Musculoskeletal pain is common in sport school students and coincides with worse health status and with a younger biological age in boys. The high prevalence of pain should be acknowledged by coaches and student healthcare workers in order to promote a healthy and sustainable development in young athletes.

\section{INTRODUCTION}

'No pain, no gain' is a motto frequently used in sport to make individuals work harder for results, even if it hurts. In youth sports, musculoskeletal pain is often studied from the standpoint of sports injuries, ${ }^{1}$ but pain conditions in which the athlete still participates in sport, and its association with maturity, health status and sports performance, are rarely mentioned in the literature.

Pain is a multifaceted state and is defined as 'An unpleasant sensory and emotional experience associated with actual or potential tissue damage or described in terms of such damage', ${ }^{2}$ meaning that pain does not
What are the new findings?

Musculoskeletal pain is common in adolescent sport school students.

- Constant pain negatively affects self-reported health status.

- Constant pain coincides with a younger biologica age in boys.

How might it impact on clinical practice in the near future?

Pain needs to be acknowledged in adolescent sport school students.

- Coaches and school personnel should have a preventive action plan to promote a healthy and sustainable development for young athletes.

necessarily have to be associated with injuries. Pain is common in adolescents, with a prevalence of $4 \%-40 \%$. In general, girls appear to be more afflicted with pain than boys. ${ }^{3}$ There is a discrepancy regarding the relationships between pain, health status and participation in sport. Adolescents who participate in sports generally report having better general health than their inactive counterparts, ${ }^{4}$ but there is a dose-response relationship between pain and time spent participating in sports ${ }^{5}$ that can negatively affect the health status of active adolescents. ${ }^{6}$ Adolescents with pain may continue to have pain as young adults, which is a matter for concern.

The risk of injury is higher during adolescent years because of structural changes in the skeleton, muscles and tendons. ${ }^{8}$ Consensus recommendations suggest that definitions of sports injuries should incorporate time lost from participation, ${ }^{1}$ which is why there is little information on pain conditions that do not affect participation in sports. There is a need for sports coaches to monitor training load during adolescence and to adapt the load according to the physical maturity of the athlete-in order to prevent injuries and to optimise athletic development. ${ }^{910}$ Few studies 
have investigated the perception of pain and biological maturity in adolescents who are active in sports. In the general population, pubertal age was found to be a better predictor of both multiple pain and pain prevalence than chronological age in adolescent boys and girls, indicating that it may be important to assess physical maturity together with pain. ${ }^{112}$ The aim of this study was to investigate the frequency of musculoskeletal pain and its association with maturity offset, health status and sports performance in 14-year-old sport school students.

\section{METHODS}

This cross-sectional study was part of the project 'Malmö Youth Sport Study'. Three age cohorts of Swedish seventh grade students ( 14 years old; $n=233$ ) from a sports school were asked to participate in the study. The school enrols young athletes who are highly ranked in their sports and who are aiming for an elite career in the future. After a qualifying round, students are admitted to the school in one sport. They practice their sport during school hours (450 min per week) and attend regular training and competitions on their leisure time. Contact sports (basketball, football, floorball and ice hockey), non-contact sports (swimming, athletics, tennis, badminton and squash) and aesthetic sports (diving, figure skating and artistic gymnastics) are represented at the school.

Anthropometrics were measured, questionnaires were distributed and sports performance measures were taken during the spring of 2014, 2015 and 2016. The exclusion criteria were having a birth date before or after ordinary age cohort, reports of injuries and/or non-participation in lower extremity performance tests.

The research project 'Malmö Youth Sport Study' was approved by the Regional Ethical Review Board in Lund, Sweden (2012/745, 2014/270 and 2017/325). Participation in the study was voluntary and an informed consent document was signed by both the student and his/her guardian before entering the study.

\section{Testing procedures}

All the students performed an individual 5-10 min warm-up. Anthropometrics, questionnaires and sports performance tests were measured by trained leaders and performed in random order at the school during 1 day or over no more than 2 days ( $\leq 1$ week apart) at the school.

\section{Anthropometric measures}

Anthropometric measurements of height, sitting height and body weight were performed to estimate maturity offset. Maturity offset is an assessment of maturity in relation to peak height velocity (PHV). Negative values indicate years to PHV and positive values indicate years passed since PHV. ${ }^{13}$ A stadiometer was used to measure height and sitting height to the nearest $0.1 \mathrm{~cm}$. Two measurements were taken in each test and if the results differed by more than $0.4 \mathrm{~cm}$, a third measurement was taken. Body weight was measured with a digital personal scale with column, to the nearest $0.1 \mathrm{~kg}$. Two measurements were taken and if the results differed by more than $0.1 \mathrm{~kg}$, a third measurement was taken. The mean of two values or the median of three values was used in analyses of height, sitting height and weight. Maturity offset was calculated according to sex-specific equations for boys $\left(\mathrm{R}^{2}=0.89\right.$, $\mathrm{SE}$ of estimate $=0.59$ and $\left.\mathrm{SD}=0.65\right)$ and girls $\left(\mathrm{R}^{2}=0.89\right.$, $\mathrm{SE}$ of estimate $=0.57$ and $\left.\mathrm{SD}=0.68\right){ }^{13}$

\section{Questionnaires}

The prevalence of musculoskeletal pain was evaluated using two items. A pain mannequin with 18 predefined body regions ${ }^{14}$ was used to examine the frequency of pain. Each region had six response options: never/ rarely/monthly/weekly/more than once a week/almost daily. ${ }^{6}$ In addition, a numeric rating scale $(0-10$, best to worst) was used to assess pain intensity during the previous week. The pain mannequin ${ }^{14}$ and the numeric rating scale ${ }^{15}$ have been validated and have been used in previous studies.

The EQ-5D questionnaire measures health status and covers five domains: mobility, self-care, usual activities, pain/discomfort and anxiety/depression. Every domain contains three response options (no problems, some problems and extreme problems). Responses were transformed into a UK index ranging from 0.00 to 1.00 (worst health to best health). ${ }^{1617}$

\section{Sports performance tests}

Speed was assessed with the $20 \mathrm{~m}$ sprint $^{18}$ and agility with the T-test. ${ }^{19}$ The validated and reliable T-test was performed in accordance with protocol according to Pauole $e t a l,{ }^{19}$ but with cones. Both tests were performed on an indoor track surface and with the starting line placed $0.5 \mathrm{~m}$ before the infrared single-beam timing gates (MuscleLab; Ergotest Innovation, Porsgrunn, Norway). Three trials were done for $20 \mathrm{~m}$ sprint, and two approved trials were done for T-test, and the fastest time for each test was recorded to the nearest $0.01 \mathrm{~s}$ for use in analyses.

Power in the lower extremities was assessed with the counter-movement jump with arm swing (CMJ-AS) ${ }^{20}$ and measured with an infrared mat (MuscleLab; Ergotest Innovation). ${ }^{21}$ Three attempts in a row were made, and the highest jump was recorded to the nearest $0.1 \mathrm{~cm}$ and used in analysis.

Grip strength was assessed with a hand-grip dynamometer with a steel spring of $40 \mathrm{~kg}$ resistance (KERN Sohn GmbH, Balingen, Germany) according to the Southampton protocol, ${ }^{22}$ with arm resting on a table. Three consecutive trials were performed on each hand and the maximum value was recorded to the nearest $0.1 \mathrm{~kg}$ (independent of hand) and used in analysis. ${ }^{22}$

\section{Statistical analyses}

The six response options for frequency of pain in each region of the body were collapsed into three categories: never and rarely were categorised as 'infrequent pain', monthly and weekly as 'frequent pain' and more than once a week and almost daily as 'constant pain'. Students 
who reported having pain in at least one body region were categorised into one of the three pain groups, according to highest reported frequency. Analysis of variance was used for pain group comparisons, but gave little information, why a Student's t-test between the most extreme groups (infrequent pain and constant pain), stratified for sex, was used. Analysis of covariance was used for analysing associations between sports performance parameters (dependent variables) and pain groups and maturity offset (independent variables). The data were analysed with IBM SPSS Statistics V.24.0 (IBM, Armonk, New York, USA) and statistical significance was assumed at $\mathrm{p}<0.05$.

\section{RESULTS}

Two hundred and twenty out of 233 registered students were interested in participating in the study. Seven of the 220 did not return the consent form and 11 missed the test session. Students were excluded from the study if they were born before or after their age cohort $(n=2)$ or if they reported injuries and/or did not participate in the performance tests $(\mathrm{n}=22)$. This resulted in a total dropout of 42 students ( $38 \%$ of them girls), leaving 178 $(83.6 \%)$ out of 213 students in the final sample, 108 boys $(60.7 \%)$ and 70 girls $(39.3 \%)$.

Height for boys ranged from $145.0 \mathrm{~cm}$ to $187.5 \mathrm{~cm}$ and weight from $37.3 \mathrm{~kg}$ to $82.7 \mathrm{~kg}$; height for girls ranged from $148.4 \mathrm{~cm}$ to $176.5 \mathrm{~cm}$ and weight from $40.3 \mathrm{~kg}$ to $71.7 \mathrm{~kg}$. Maturity offset ranged from -1.87 to 1.51 for boys and from 0.41 to 2.47 for girls. Out of 178 students, 167 could be categorised into pain groups: infrequent pain $(18.6 \%)$, frequent pain $(50.9 \%)$ and constant pain $(30.5 \%)$. See table 1 for descriptive data. In the constant pain group, the most commonly reported pain regions were the knees and the lower legs/feet.

\section{Constant pain versus infrequent pain}

Boys in the constant pain group had higher pain intensity $(\mathrm{p}<0.000)$, had a worse score for health status $(\mathrm{p}<0.000)$ and had a worse sports performance regarding $20 \mathrm{~m}$ sprint, agility T-test and CMJ-AS than boys with infrequent pain. Boys in the constant pain group also had a

Table 1 Results of comparisons between boys and girls for anthropometrics and demographics, questionnaires and sports performance tests

\begin{tabular}{|c|c|c|c|c|}
\hline & $\begin{array}{l}\text { All }(n=178) \\
\text { Mean } \pm S D\end{array}$ & $\begin{array}{l}\text { Boys }(n=108) \\
\text { Mean } \pm \text { SD }\end{array}$ & $\begin{array}{l}\text { Girls }(n=70) \\
\text { Mean } \pm S D\end{array}$ & $\begin{array}{l}\text { Boys vs Girls } \\
\mathrm{P} \text { values }\end{array}$ \\
\hline \multicolumn{5}{|c|}{ Anthropometrics and demographics } \\
\hline Height (cm) & $165.5 \pm 8.7$ & $167.1 \pm 9.6$ & $163.1 \pm 6.4$ & 0.001 \\
\hline Weight (kg) & $54.0 \pm 9.0$ & $54.0 \pm 10.2$ & $54.2 \pm 6.9$ & 0.87 \\
\hline $\mathrm{BMI}\left(\mathrm{kg} \mathrm{bw} / \mathrm{m}^{2}\right)$ & $19.6 \pm 2.2$ & $19.2 \pm 2.1$ & $20.3 \pm 2.1$ & $<0.000$ \\
\hline Chronological age (years) & $13.94 \pm 0.26$ & $13.94 \pm 0.26$ & $13.94 \pm 0.27$ & 0.98 \\
\hline Maturity offset (years) & $0.49 \pm 1.14$ & $-0.27 \pm 0.75$ & $1.66 \pm 0.43$ & $<0.000$ \\
\hline \multicolumn{5}{|l|}{ Sports } \\
\hline Contact & $127(71.3 \%)$ & $90(83.3 \%)$ & 37 (52.9\%) & \\
\hline Non-contact & 38 (21.3\%) & $13(12.0 \%)$ & 25 (35.7\%) & $<0.000^{*}$ \\
\hline Aesthetic & $13(7.3 \%)$ & $5(4.6 \%)$ & $8(11.4 \%)$ & \\
\hline \multicolumn{5}{|l|}{ Questionnaires } \\
\hline \multicolumn{5}{|l|}{ Pain groups } \\
\hline Infrequent pain & $31(18.6 \%)$ & $22(22.0 \%)$ & $9(13.4 \%)$ & \\
\hline Frequent pain & $85(50.9 \%)$ & $51(51.0 \%)$ & 34 (50.7\%) & $0.27^{\star}$ \\
\hline Constant pain & 51 (30.5\%) & 27 (27.0\%) & 24 (35.8\%) & \\
\hline Pain intensity† & $3.0 \pm 2.2$ & $3.0 \pm 2.2$ & $3.1 \pm 2.1$ & 0.70 \\
\hline EQ-5D & $0.86 \pm 0.13$ & $0.87 \pm 0.13$ & $0.85 \pm 0.14$ & 0.19 \\
\hline \multicolumn{5}{|l|}{ Sports performance tests } \\
\hline 20 m sprint (s) & $3.36 \pm 0.19$ & $3.33 \pm 0.20$ & $3.40 \pm 0.16$ & 0.01 \\
\hline Agility T-test (s) & $10.82 \pm 0.62$ & $10.66 \pm 0.62$ & $11.06 \pm 0.56$ & $<0.000$ \\
\hline CMJ-AS (cm) & $34.2 \pm 5.8$ & $35.4 \pm 6.0$ & $32.4 \pm 5.0$ & 0.001 \\
\hline Grip strength (kg) & $29.7 \pm 6.3$ & $30.9 \pm 7.0$ & $27.9 \pm 4.6$ & 0.001 \\
\hline
\end{tabular}

The results were analysed with Student's t-test and are presented as mean \pm SD or were analysed with $\chi^{2}$ test and are presented as $\mathrm{n}(\%)$.

${ }^{*}$ Analysed with $\chi^{2}$ test.

†0-10 points, scored from best to worst $(n=163)$.

$\ddagger 0.00-1.00$, scored from worst to best $(n=172)$.

$\mathrm{BMI}$, body mass index; Bw, body weight; CMJ-AS, counter-movement jump with arm swing. 
Table 2 Results of comparisons within the one sex between the infrequent pain and constant pain groups for anthropometrics and demographics, questionnaires and sports performance tests

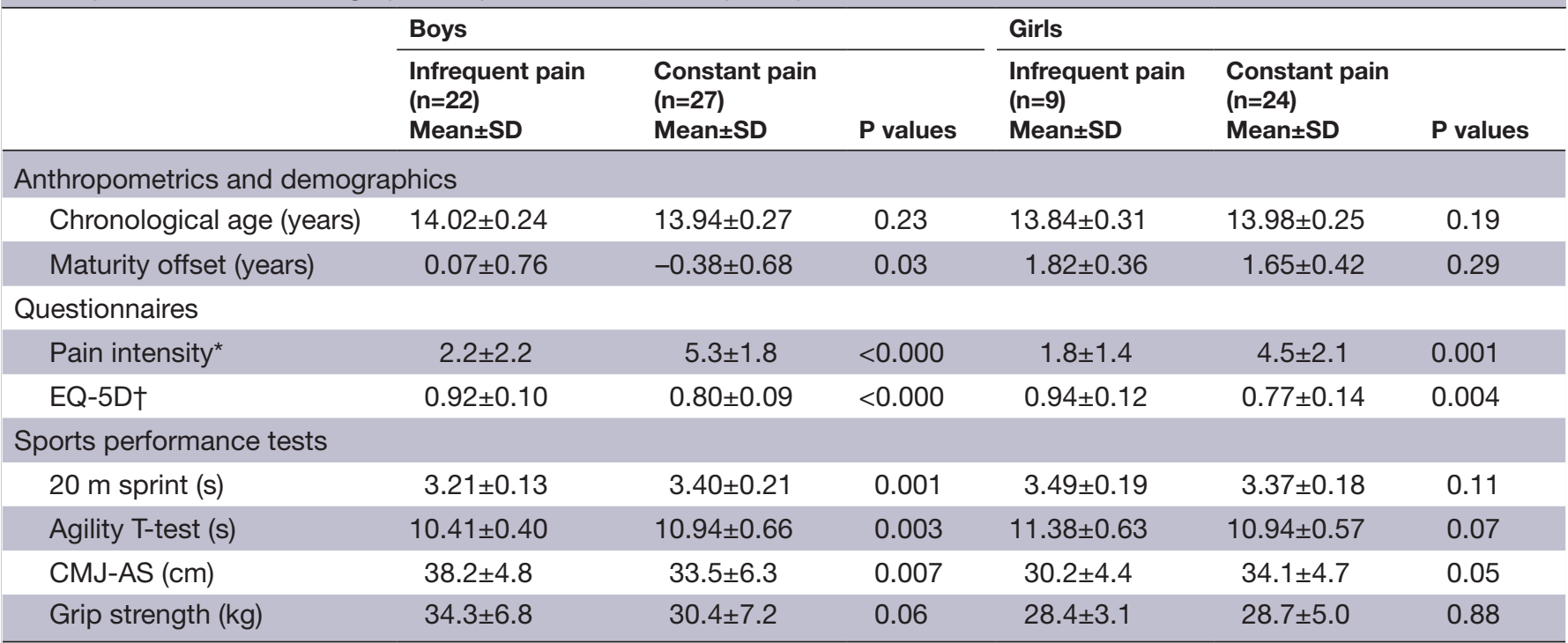

The results were analysed with Student's t-test and are presented as mean \pm SD.

${ }^{*} 0-10$ points, scored from best to worst.

†0.00-1.00, scored from worst to best.

CMJ-AS, counter-movement jump with arm swing.

lower mean value for maturity offset $(\mathrm{p}=0.03)$, indicating a younger biological age. Girls in the constant pain group generally reported having a higher intensity of pain $(p=0.001)$ and they had worse scores for health status $(p=0.004)$, but there was no difference in maturity offset $(\mathrm{p}=0.29)$ and sports performance between these girls and the girls in the infrequent pain group (table 2).

\section{Associations between sports performance, maturity and pain}

A higher value for maturity offset was associated with a better sports performance in $20 \mathrm{~m}$ sprint and grip strength in boys, but only in grip strength in girls. Pain group categorisation (infrequent pain to constant pain) was associated to a worse sports performance in $20 \mathrm{~m}$ sprint, agility T-test and CMJ-AS in boys. In girls, the results were reversed with better performances in 20 $\mathrm{m}$ sprint $(\mathrm{p}=0.06)$, agility T-test $(\mathrm{p}=0.06)$ and CMJ-AS $(\mathrm{p}=0.01)$ for higher reported pain frequency (tables 3 and 4).

\section{DISCUSSION}

In this study, one out of three students who attended a sports school reported having pain on an almost daily basis, and this was associated with higher reported pain intensity and a worse health status than in students who reported that they rarely experienced pain. The boys in the constant pain group were biologically younger and performed worse regarding almost all measures of performance than the boys in the infrequent pain group. The association between worse sports performance and pain maintained even when adjusting for maturity offset. There were no significant differences in maturity or in sports performance between girls with infrequent pain and girls with constant pain. Belonging to the groups of frequent pain or constant pain seemed to be associated with a better sports performance in girls.

Emphasis is being constantly placed on the roles of physical activity and sport as ways of enhancing health, ${ }^{23}$ but in this study, we found that as many as four out of five adolescent athletes experienced pain either frequently or constantly. Bergeron $e t a l^{24}$ stated in their consensus statement on athletic development in youths that there should be a striving towards health and sustainability. As in the general population, ${ }^{6} 25$ the students in this study who experienced pain also had a worse reported health

Table 3 Results of relationships between sports performance, physical maturity and pain groups in boys ( $n=100)$

\begin{tabular}{|c|c|c|c|c|}
\hline & 20 m sprint (s) & Agility T-test (s) & CMJ-AS (cm) & Grip strength (kg) \\
\hline & $\beta$-est $(95 \% \mathrm{Cl})$ & $\beta$-est $(95 \% \mathrm{Cl})$ & $\beta$-est $(95 \% \mathrm{Cl})$ & $\beta$-est $(95 \% \mathrm{Cl})$ \\
\hline Maturity offset (years) & $-0.06(-0.11$ to -0.01$)$ & $0.01(-0.15$ to 0.17$)$ & $1.4(-0.1$ to 3.0$)$ & 7.4 (6.2 to 8.6$)$ \\
\hline Pain groups ${ }^{\star}$ & $0.08(0.02$ to 0.13$)$ & 0.27 (0.09 to 0.45$)$ & $-2.0(-3.7$ to -0.30$)$ & $-0.2(-1.5$ to 1.1$)$ \\
\hline
\end{tabular}

The results were analysed with an analysis of covariance and are presented as $\beta$-estimate ( $\beta$-est) and $95 \% \mathrm{Cl}$.

*Infrequent pain=1, frequent pain=2 and constant pain=3.

CMJ-AS, counter-movement jump with arm swing. 
Table 4 Results of relationships between sports performance, physical maturity and pain groups in girls ( $n=67)$

\begin{tabular}{|c|c|c|c|c|}
\hline & $20 \mathrm{~m}$ sprint (s) & Agility T-test (s) & CMJ-AS (cm) & Grip strength (kg) \\
\hline & $\beta$-est $(95 \% \mathrm{Cl})$ & $\beta$-est $(95 \% \mathrm{Cl})$ & $\beta$-est $(95 \% \mathrm{Cl})$ & $\beta$-est $(95 \% \mathrm{Cl})$ \\
\hline Maturity offset (years) & $-0.06(-0.16$ to 0.03$)$ & $-0.05(-0.39$ to 0.29$)$ & $1.8(-1.0$ to 4.6$)$ & 6.6 (4.4 to 8.8$)$ \\
\hline Pain groups ${ }^{\star}$ & $-0.06(-0.12$ to 0.001$)$ & $-0.20(-0.40$ to 0.01$)$ & 2.3 (0.6 to 4.0$)$ & $0.9(-0.5$ to 2.2$)$ \\
\hline
\end{tabular}

The results were analysed with an analysis of covariance and are presented as $\beta$-estimate ( $\beta$-est) and $95 \% \mathrm{Cl}$.

*Infrequent pain=1, frequent pain=2 and constant pain=3.

CMJ-AS, counter-movement jump with arm swing.

status. Rathleff et at used a similar questionnaire to assess frequency of pain and one out of five 14-year-olds experienced pain on an almost daily basis. One in three reported having a high frequency of pain in the present study, which was slightly higher than in the study by Rathleff et al..$^{6}$

Health status is generally worse in girls, but there were no differences between boys and girls in this study. It is possible that sports have a protective effect on health status when comparing with those who experience a similar frequency of pain in the general population, but further studies are needed in this area. The differences found within sexes and between pain groups in health status can be considered to have clinical implications, as indicated by a mean difference of 0.074 in the EQ-5D. ${ }^{26}$

Physical maturity status differed in boys and girls. This is normal, since girls generally enter PHV at the age of 12 years, as compared with boys who generally enter it at 14 years of age. ${ }^{27}$ Because of the time point for data collection, all the girls in this study had already passed PHV. In addition to this, there is the factor of early selection in sports whereby those who mature early and average maturers are selected at the expense of the late maturers. ${ }^{28}$ In the general population, dispersion of maturity offset is 1 year, ${ }^{29}{ }^{30}$ but the SD for girls in this study sample was less than 6 months. A similar effect was also seen in boys, though with a wider distribution than for girls. This means that our study sample was quite narrow regarding age range, which could indicate that most of the students had been selected because they were early maturers relative to the general population. Since the distribution into pain groups was not different in boys and girls and most girls had passed their PHV, it might be that the reasons for having pain may differ depending on whether or not an adolescent has passed his or her PHV.

Noon $e t a l^{31}$ have studied recommended training loads in youth elite sports programmes and have found an increase in muscle soreness, stress and fatigue and a decrease in sport performance postseason compared with preseason. These findings indicate that there may be an imbalance between stress and recovery during the season, which also affects the subject's perception of well-being. ${ }^{31}$ Reports of frequent pain may indicate a decrease in perceived recovery in sport school students, which may increase the risk of injury. ${ }^{32}$ The injury incidence in 15-19-year-old students from the Swedish National Sports High Schools was approximately 30\% and the risk of injury increased with poor sleep patterns and poor nutrition intake. ${ }^{33}$ This indicates the need for a holistic perspective on adolescents' elite careers. Pain is a complex phenomenon. King et $a \hat{\imath}$ highlights increasing age and female sex as risk factors for pain in adolescents. Psychosocial factors, such as being sad, may affect the perception of pain in a negative way. ${ }^{3}$ More quantitative and qualitative studies are needed in order to understand the different reasons for why sport school students often experience pain.

\section{Limitations}

Students were involved in many different sports in this study sample, which may have affected the result. Contact sports have a higher incidence of injury than non-contact sports and aesthetic sports ${ }^{34}$ and this may affect reporting of pain. The sports performance tests were general, and they were not optimal for students engaged in ice sports ${ }^{35}$ or water sports. Even so, we decided to study the concept of the sport school as one entity. Because of the small study sample from the school, it may be difficult to generalise the results.

There is some uncertainty in the calculation of maturity offset, which should be considered. It has been suggested that the predicted PHV is overestimated in older individuals and underestimated in younger individuals ${ }^{30}$ and that the equation also overestimates predicted PHV in girls more than in boys. ${ }^{29}$ However, the prediction appears to be most accurate around PHV for average maturing boys between 12 and 16 years and average maturing girls between 11 and 13 years, ${ }^{29}{ }^{30}$ which correspond to the ages in the study sample. The use of the equations in athletic adolescents requires further validation. ${ }^{28}$

\section{Future directions}

Pain (irrespective of cause) is common in youth athletes and, as seen in this study, it may have a negative effect on their health status. Pain can remain long after the athlete has recovered from an injury, and guidelines on how coaches, student healthcare workers and school personnel should handle this and support the young athlete are still scarce in literature. There is a need for recommendations in youth sports that properly address the biopsychosocial aspect of pain. Pain management in adult elite athletes has recently received attention, ${ }^{36}{ }^{37}$ but more research is needed in order for us to understand the complexity of pain in very physically active adolescents. 
Finally, there is a need for further longitudinal studies on this subject in order for us to more clearly establish possible relationships between pain, maturity offset, health and sports performance-and where nutrition may also be an important factor to investigate. Moreover, reference groups from general schools will be needed to determine whether or not potential relationships are sport-specific.

\section{CONCLUSION}

Musculoskeletal pain is common in sport school students and it appears to coincide with worse health status and with a younger biological age in boys. The high prevalence of pain should be acknowledged by coaches, student healthcare workers and school personnel in order to promote a healthy and sustainable development for young athletes who are aiming for future elite careers. More studies are needed to establish possible long-term relationships between pain, maturity, health status and sports performance.

Acknowledgements We thank Malmö Idrottsgrundskola, Malmö Idrottsakademi (Malmö Sports Academy) and the students who were very helpful during data collection. A special thanks to Lie Kylborn, teacher in physical education, for organising the test sessions.

Contributors JSM: Formulation of research question, study design, data collection, analysis and interpretation of results and preparation of manuscript. MCO: Formulation of research question, study design, data collection, interpretation of results and revision of manuscript. SB: Interpretation of results and revision of manuscript. AB: Formulation of research question, study design, data collection, analysis and interpretation of results and revision of manuscript. All the authors have approved the final manuscript.

Funding The study was supported financially by Halmstad University; Spenshult Research and Development Center, Halmstad; Region Halland (grant numbers HALLAND-469111 and HALLAND-639101); and the Mayflower Charity Foundation, Sweden. The sources of funding were not involved in the study design, data collection, analysis of data, interpretation of data, writing of the manuscript, or submission for publication.

Competing interests None declared.

Patient consent Parental/guardian consent obtained.

Ethics approval The Regional Ethical Review Board in Lund, Sweden.

Provenance and peer review Not commissioned; externally peer reviewed.

Open access This is an Open access article distributed in accordance with the Creative Commons Attribution Non Commercial (CC BY-NC 4.0) license, which permits others to distribute, remix, adapt, build upon this work non-commercially, and license their derivative works on different terms, provided the original work is properly cited, appropriate credit is given, any changes made indicated, and the use is non-commercial. See: http://creativecommons.org/licenses/by-nc/4.0/.

\section{REFERENCES}

1. Goldberg AS, Moroz L, Smith A, et al. Injury surveillance in young athletes: a clinician's guide to sports injury literature. Sports Med 2007;37:265-78

2. The International Association for the Study of Pain. IASP Taxonomy 2012. https://www.iasp-pain.org/Education/Content.aspx? ItemNumber $=1698 \&$ navltemNumber $=576 \#$ Pain (accessed $11 \mathrm{Ju}$ 2017).

3. King S, Chambers CT, Huguet A, et al. The epidemiology of chronic pain in children and adolescents revisited: a systematic review. Pain 2011;152:2729-38.

4. Penedo FJ, Dahn JR. Exercise and well-being: a review of mental and physical health benefits associated with physical activity. Curr Opin Psychiatry 2005;18:189-93.
5. Kamada M, Abe T, Kitayuguchi J, et al. Dose-response relationship between sports activity and musculoskeletal pain in adolescents. Pain 2016;157:1339-45.

6. Rathleff MS, Roos EM, Olesen JL, et al. High prevalence of daily and multi-site pain--a cross-sectional population-based study among 3000 Danish adolescents. BMC Pediatr 2013;13:191.

7. Brattberg G. Do pain problems in young school children persist into early adulthood? A 13-year follow-up. Eur J Pain 2004;8:187-99.

8. Merkel DL. Youth sport: positive and negative impact on young athletes. Open Access J Sports Med 2013;4:151-60.

9. Soligard T, Schwellnus M, Alonso JM, et al. How much is too much? (Part 1) International Olympic Committee consensus statement on load in sport and risk of injury. Br J Sports Med 2016;50:1030-41.

10. van der Sluis A, Elferink-Gemser MT, Brink MS, et al. Importance of peak height velocity timing in terms of injuries in talented soccer players. Int J Sports Med 2015;36:327-32.

11. LeResche L, Mancl LA, Drangsholt MT, et al. Relationship of pain and symptoms to pubertal development in adolescents. Pain 2005;118:201-9.

12. Rhee $H$. Relationships between physical symptoms and pubertal development. J Pediatr Health Care 2005;19:95-103.

13. Mirwald RL, Baxter-Jones AD, Bailey DA, et al. An assessment of maturity from anthropometric measurements. Med Sci Sports Exerc 2002;34:689-94.

14. Bergman $S$, Herrström $P$, Jacobsson LT, et al. Chronic widespread pain: a three year followup of pain distribution and risk factors. $J$ Rheumatol 2002;29:818-25.

15. von Baeyer CL, Spagrud LJ, McCormick JC, et al. Three new datasets supporting use of the Numerical Rating Scale (NRS-11) for children's self-reports of pain intensity. Pain 2009;143:223-7.

16. EuroQol Group. EuroQol-a new facility for the measurement of health-related quality of life. Health Policy 1990;16:199-208.

17. Dolan P. Aggregating health state valuations. J Health Serv Res Policy 1997;2:160-5.

18. Comfort P, Stewart A, Bloom L, et al. Relationships between strength, sprint, and jump performance in well-trained youth soccer players. J Strength Cond Res 2014;28:173-7.

19. Pauole K, Madole K, Garhammer J. Reliability and Validity of the T-Test as a Measure of Agility, Leg Power, and Leg Speed in CollegeAged Men and Women. Journal of Strength and Conditioning Research 2000;14:443-50.

20. Slinde F, Suber C, Suber L, et al. Test-retest reliability of three different countermovement jumping tests. J Strength Cond Res 2008;22:640-4.

21. Markovic G, Dizdar D, Jukic I, et al. Reliability and factorial validity of squat and countermovement jump tests. J Strength Cond Res 2004;18:551-5.

22. Roberts $\mathrm{HC}$, Denison $\mathrm{HJ}$, Martin $\mathrm{HJ}$, et al. A review of the measurement of grip strength in clinical and epidemiological studies: towards a standardised approach. Age Ageing 2011;40:423-9.

23. World Health Organization. Physical activity and young people. 2011. http://www.who.int/dietphysicalactivity/factsheet_young people/en/ (accessed 18 Jul 2017).

24. Bergeron MF, Mountjoy M, Armstrong N, et al. International Olympic Committee consensus statement on youth athletic development. $\mathrm{Br}$ J Sports Med 2015;49:843-51.

25. Paananen M, Taimela S, Auvinen J, et al. Impact of self-reported musculoskeletal pain on health-related quality of life among young adults. Pain Med 2011;12:9-17.

26. Wille N, Badia X, Bonsel G, et al. Development of the EQ-5D-Y: a child-friendly version of the EQ-5D. Qual Life Res 2010;19:875-86.

27. Baxter-Jones ADG, Eisenmann JC, Sherar LB. Controlling for Maturation in Pediatric Exercise Science. Pediatr Exerc Sci 2005;17:18-

28. Malina RM, Rogol AD, Cumming SP, et al. Biological maturation of youth athletes: assessment and implications. Br J Sports Med 2015;49:852-9.

29. Malina RM, Kozieł SM. Validation of maturity offset in a longitudina sample of Polish girls. J Sports Sci 2014;32:1374-82.

30. Malina RM, Kozieł SM. Validation of maturity offset in a longitudinal sample of Polish boys. J Sports Sci 2014;32:424-37.

31. Noon MR, James RS, Clarke ND, et al. Perceptions of well-being and physical performance in English elite youth footballers across a season. J Sports Sci 2015;33:2106-15.

32. Brink MS, Visscher C, Arends S, et al. Monitoring stress and recovery: new insights for the prevention of injuries and illnesses in elite youth soccer players. Br J Sports Med 2010;44:809-15.

33. von Rosen P, Frohm A, Kottorp A, et al. Too little sleep and an unhealthy diet could increase the risk of sustaining a new injury in adolescent elite athletes. Scand J Med Sci Sports 2017;27:1364-71. 
34. Malisoux L, Frisch A, Urhausen A, et al. Monitoring of sport participation and injury risk in young athletes. J Sci Med Sport 2013;16:504-8.

35. Durocher JJ, Guisfredi AJ, Leetun DT, et al. Comparison of on-ice and off-ice graded exercise testing in collegiate hockey players. Appl Physiol Nutr Metab 2010;35:35-9.
36. Hainline B, Derman W, Vernec A, et al. International Olympic Committee consensus statement on pain management in elite athletes. Br J Sports Med 2017;51:1245-58.

37. Hainline B, Turner JA, Caneiro JP, et al. Pain in elite athletesneurophysiological, biomechanical and psychosocial considerations: a narrative review. Br J Sports Med 2017;51:1259-64. 